flexiones sobre las nuevas fuerzas de cambio en la educación superior", en MOLLIS, Marcela (Comp.): Las Universidades en América Latina: ¿Reformadas o Alteradas? La cosmética del poder financiero. CLACSO. Bs. As.

- GRUPO ESPECIAL SOBRE EDUCACIÓN SUPERIOR (2000): La Educación Superior en los Países en Desarrollo: Peligros y Promesas. World Bank. Edición electrónica.

- KROTSCH, P.; PUIGGRÓS, A. (Comp.) (1994): Universidad y evaluación: estado del debate. Aique/REI/IDEAS.

- MARQUIS, C. y otros (1998), Desarrollo y acreditación de los posgrados en Argentina, Brasil y México: Textos para una Mirada Comparativa, M.C.E., Secretaria de Politicas Universitarias, Buenos Aires.

- MARTÍN, Julio (2000): La acreditación universitaria en el MERCOSUR: ordenamiento legal. Universidad Autónoma de Asunción. Fondo Editorial. Asunción.

- MOLLIS, Marcela (2001): La Universidad argentina en tránsito. Ensayo para jóvenes y no tan jóvenes. FCE. Bs. AS

- MOURA DE CASTRO, Claudio; LEVY, D (1997): La Educación Superior en América Latina y el Caribe. Documento de Estrategia. BID. Edición electrónica.

- NAISHTAT, F.(comp.) (2001): Filosofias de la Universidad y conflicto de Racionalidades, Colihue. Bs.As.

- NEAVE, G.; VUGHT, V. (1994): Prometeo encadenado. Estado y Educación Superior en Europa, Gedisa.

- OROZCO SILVA, Luis E. La calidad de la universidad. Más allá de toda ambigüedad. Versión electrónica.

- OSSORIO, Alfredo (2003): Planeamiento Estratégico. INAP. Edición electrónica.

- PÉREZ LINDO, Augusto (2003): Universidad, conocimiento y reconstrucción nacional. Editorial Biblos. Bs. AS.

- QUIVY, R y CAMPENHOUDT, L (1999): Metodología de investigación en Ciencias Sociales. Limusa. México.

- SANCHEZ MARTÍNEZ, Eduardo (2000): La legislación sobre Educación Superior en Argentina. Entre rupturas, continuidades y transformaciones. IESAL/ UNESCO. Edición electrónica.

- STUBRIN Adolfo L. Una encrucijada interpretativa acerca de la acreditación de las carreras de grado, en www.coneau.gov.ar/que_es/document/publicaciones/publicaciones.html

- TORRES, Carlos (Comp.) (2002): Paulo Freire y la agenda de la educación latinoamericana en el siglo XXI. CLACSO. Bs. As.

- VAIN, Pablo: La evaluación de la docencia universitaria: un problema complejo. CONEAU. Edición electrónica.

- VROEIJENSTIJN, A. I. (1995): Capítulo 1. El nuevo interés por la evaluación de la calidad de la educación superior en Improvement and Accountability: Navigating between Silla and Caribdis, London, Jessica Kingsley. Traducción del equipo técnico CONEAU. Versión electrónica.

\section{UNA HISTÓRICA TENSIÓN: LA DISTRIBUCIÓN DE COMPETENCIAS EN MATERIA EDUCATIVA ENTRE LA NACIÓN Y LAS PROVINCIAS}

Prof. Lic Maria Catalina Nosiglia (Universidad de Buenos Aires)

Prof. Lic Sergio Trippano

(Universidad de Buenos Aires)

(Universidad Nacional de Rosario)

\section{Resumen}

Este articulo aborda cuestiones del gobierno de la educación, en particular, los aspectos referidos a la organización institucional del sistema educativo, es decir, a la distribución de competencias en materia educativa entre la Nación y las provincias y su impacto en la configuración y regulación del sistema educativo, para lograr cierta unidad, en un país federal como la Argentina.

Se intentará caracterizar desde la sanción de la Constitución de 1853, como se fue estableciendo y articulando esta "división de tareas educativas" entre las distintas jurisdicciones. A tal fin, se analizan las políticas seguidas en materia de: a) prestación y supervisión de los servicios educativos, b) definición del currículo, c) regulación de la validez de los títulos y c) financiamiento educativo. Se considera que tales cuestiones expresan con mayor claridad las estrategias seguidas por el gobierno nacional para influir centralmente en la orientación del sistema educativo nacional.

\section{Palabras clave:}

Federalismo, gobierno, currículo, diplomas y financiamiento educativo

\section{Summary}

This article approaches questions of the government of the education, in individual, the aspects referred to the institutional organization of the educative system, that is to say, to the distribuicion of the competitions in educative matter between the nation and the provinces and their impact in 
the configuration and regulation of the educative system to obtain certain unit in a federal country like Argentina. It will be tried to characterize since the Constitution of 1853 how was establish this "division of educative tasks" between the different jurisdictions. To such aim, the policies followed will be analyzed in the matter of: a) creation and supervision of the schools, b) definition of curriculo, c) regulation of the validity of diplomas and c) educational finances. It is considered that such questions express with greater clarity the strategies followed by the national government to influence centrally in the orientation of the national educative

\section{Key words:}

Federalization, government, currículo, diplomas and educational finances.

\section{Introducción}

Con la culminación de las transferencias de escuelas de jurisdicción nacional a las provincias en 1992 y con la sanción e implementación desigual en las provincias de la Ley Federal de Educación en 1993, se reactualizó el problema de establecer cierta unidad del sistema educativo en un pais donde la prestación de los servicios educativos, corresponde a las provincias en el marco del federalismo.

En este trabajo se aborda la problemática del gobierno de la educación y particularmente, la organización institucional del sistema educativo, es decir, cómo fueron distribuidas históricamente en la normativa educativa desde la Constitución nacional de 1953, las competencias en materia educativa entre la nación y las provincias y su impacto en la configuración y regulación del sistema educativo.

A tal fin se analizarán algunas cuestiones centrales referidas a las politicas seguidas en materia de prestación y supervisión de los servicios educativos, de definición del curriculo, de regulación de la validez de los títulos y del financiamiento. Estos son los instrumentos politicos principales que históricamente fueron utilizados por el Estado nacional, para regular el sistema educativo en su conjunto

\section{La organización institucional del sistema educativo en la Constitución Nacional y las leyes}

La Constitución Nacional de 1853, como expresión de la voluntad soberana de las provincias de constituirse en una nación, fue el resultado de un largo proceso de marchas y contramarchas acerca de qué atribuciones las provincias delegaban en la nación y cuáles se reservaban como actividad propia.

El texto establece en sus artículos $5^{\circ}$ y $67^{\circ}$ inciso 16 (actualmente 75 inciso 18), la organización del sistema educativo.

Como sucede con muchos artículos de la Constitución, los especialistas en derecho constitucional y en educación así como las medidas concretas de política educativa que se diseñaron amparados en estas normas constitucionales, expresaron diferentes interpretaciones de sus alcances.

El artículo $5^{\circ}$ establece que las provincias deben asegurar, entre otras cosas, la educación primaria en sus respectivos territorios, para gozar de su autonomia. Con esta norma se intenta respetar aquello que venia ocurriendo hasta la sanción de nuestra Carta Fundamental, ya que las provincias asumieron incipientemente la responsabilidad por la educación en su territorio.

Sin embargo, a fin de garantizar el derecho a la educación y la unidad nacional, entre las competencias del Congreso de la Nación en materia educativa se determina que éste será el encargado de dictar planes de instrucción general y universitaria (75 inciso 18). Esta competencia se ve reafirmada con la Reforma Constitucional de 1994, ya que se señala que las leyes que se dicten serán de organización y de base (Art. 75 inciso 19).

De la interpretación conjunta de estos dos artículos $5^{\circ}$ y 75 inc. 18 y 19 queda de manifiesto la necesidad de que ante la organización federal de nuestro sistema educativo, la unidad del sistema se lograría, a través de la ley general de educación que debería dictar el Congreso Nacional.

Del estudio de las bases legales del sistema educativo surge que la atribución conferida al Congreso en 1853 hasta la sanción de la Ley Federal de Educación 24.195 (LFE), fue ejercida legislando en forma parcial y no articulada sobre algunos niveles educativos. (1)

Con respecto a la interpretación conjunta de los artículos 5 y 76 incisos 18 y 19 , algunos especialistas consideran que tanto las provincias como la nación tienen competencia en la formulación, supervisión y prestación del servicio educativo (Bravo, 1972 y Paviglianiti, 1988). La nación porque debe promover el bienestar general y asegurar los beneficios de la libertad (Preámbulo) y las provincias deben prestar los servicios de todos los niveles a fin de asegurar el derecho a la educación y porque no está expresamente delegada esta potestad en la nación. Para otros especialistas, la provisión de educación primaria es sólo competencia de las provincias (José Gorostiaga y Juan Maria Gutiérrez miembros de la comisión redactora del 
Proyecto de Ley de Educación encargado por Mitre en 1865, citado por Bravo, 1972 y Montenegro, 1988) y la nación debe ayudar a las provincias vía asistencia financiera. Esta es la interpretación que tuvo mayores adhesiones teóricas y concreciones en la realidad.

Del análisis histórico del accionar de la nación en materia educativa, se observa que existieron momentos en donde el estado nacional sólo colaboró de manera indirecta con las provincias mediante asistencia financiera, técnica o compensatoria y periodos en los que actuó de manera directa, es decir creando sus propias escuelas en territorios provinciales.

Entre 1853 y 1905 la Nación ayudó a las provincias fundamentalmente en términos económicos, vía leyes de subsidios para la educación primaria. A partir de esta última fecha y hasta 1970 creó sus propias escuelas primarias en territorios provinciales, a la vez que fue expandiendo los servicios de educación media y terciaria no universitaria. De aquí en adelante, disminuye su ritmo de expansión y comienza a transferir, primero las escuelas primarias a las provincias que se completa masivamente en 1978 y luego las medias y terciarias en 1992. De este modo, el Ministerio de la Nación deja de prestar servicios educativos en las provincias pasando a ser, según la expresión del Profesor Salonia, ministro de educación de Menem, "un ministerio sin escuelas".

Si la creación de escuelas primarias, medias y terciarias fue un mecanismo utilizado históricamente por la nación para difundir los valores y símbolos que consideraba importantes para lograr la unidad nacional bajo la ideologia liberal, transferidas las escuelas fue necesario desarrollar nuevos modos de regulación y control interjurisdiccionales. Por un lado, el contenido de la LFE en materia de gobierno y la estrategia utilizada para su implementación via acuerdos federales acordados en el seno del revitalizado Consejo Federal de Educación y por otro, el poder financiero y técnico diferencial de la nación; se erigieron en los nuevos mecanismos de intervención educativa central.

Paviglianiti considera que esta situación cambiante con respecto al papel de la Nación, en el período que ella analizó hasta 1985, osciló entre una centralización uniformante a una descentralización anárquica (Paviglianiti, 1988). Recientemente, otros autores que analizan el rol del Ministerio de Educación de la Nación a partir de aplicación de la Ley Federal de Educación sostienen que estamos en un periodo de recentralización de las políticas en materia educativa por una doble pérdida de autonomía: del estado nacional frente a los organismos internacionales y de los estados provinciales frente a la nación por un diferencial acceso a recursos económicos y técnicos (Nosiglia y Marquina, 1995).
Como señaläbamos, uno de los mecanismos privilegiados de articulación de la oferta educativa a nivel nacional es la legislación - de organización y de base y de instrucción general y universitaria- que debe dictar en Congreso Nacional en virtud de su atribución constitucional plasmada en el artículo 75 inciso 18 y 19 .

Es necesario destacar que toda norma esta mediada en su aplicación por las jurisdicciones educativas, las escuelas y los propios docentes. Sin embargo, desde el punto de vista formal, el sistema jurídico de nuestra república determina un orden de prelación de las normas que debe ser respetado para que las mismas sean consideradas válidas juridicamente.

El orden jerárquico de nuestras normas se basa en una norma fundamental, la Constitución, que es la fuente común de validez de todo el sistema jurídico. Las normas de orden inferior en forma decreciente son: las leyes nacionales, las constituciones provinciales y las leyes provinciales. Esta aclaración resulta imprescindible para entender porque una ley nacional debe ser respetada por las provincias. Es el caso de la LFE es la norma de base para redactar las leyes educativas provinciales.

La legislación en general es un instrumento del estado para regular su propia actividad y la de los particulares y mediante el cual se deben ajustar las conductas de los ciudadanos a los objetivos de una política.

Aunque, en lo formal, son los legisladores quienes tienen la potestad de redactar las leyes, el contenido de las mismas resulta de una multiplicidad de influencias. Siguiendo a Tiramonti y Nosiglia, se destacan: a) negociaciones entre los diferentes actores y circunstancias que en cada momento determina su contenido y sentido; b) la opinión pública en general, los intereses de los sectores sociales, sustento del elenco gobernante; y c) los diagnósticos elaborados por elenco gobernante en concordancia con los intereses de los grupos sociales en que se apoya. Al difundirse el diagnóstico se trata de crear la necesidad social de producir acciones transformadoras en el sentido recomendado por el éste (Tiramonti y Nosiglia, 1991).

Analizando el conjunto de la legislación (2) que en materia educativa fue dictada, hasta la sanción de la LFE, Héctor Bravo destaca las siguientes características: a) la inorganicidad por ausencia de una ley de base comprensiva de todos los niveles de enseñanza que hace que sean parciales e incompletas, b) la anarquia dada por lagunas o ausencias de normas o por vigencia simultánea de disposiciones contradictorias, c) la ilegalidad o inconstitucionalidad de determinadas normas que no respeta-

$$
-66-
$$$$
-67-
$$ 
ron el orden de prelación de las normas jurídicas, como por ejemplo la modificación de leyes a través de decretos y d) el incumplimiento de algunas leyes (Bravo, 1983)

Con el dictado de la LFE, algunas de estas características cambiaron, pero la organización federal de nuestro sistema educativo complejiza la tarea legislativa. Es asi, como a pesar de la existencia de esta ley muchas de las jurisdicciones educativas aún no han cambiado su normativa y se rigen por normas que, por ejemplo, en términos de estructura no respetaron lo contemplado en la LFE. Aquí, se plantea, desde el derecho, otro de los problemas del orden juridico, muchas leyes pueden ser válidas por el orden de su dictado y no ser eficaces porque no se cumplen o respetan (3). Podría decirse que la LFE gozó, de legalidad por haber sido șancionada por la mayoria de ambas cámaras legislativas, pero tuvo una legitimidad acotada por no contar con el apoyo de la oposición y de actores fundamentales como los docentes; o simplemente las provincias no la pudieron aplicar por problemas de orden político, financiero o técnico. (4)

\section{La cuestión de la validez nacional de los títulos y certificados}

Una de las cuestiones que el Estado Nacional se reservo históricamente como actividad exclusiva fue la validación nacional de los títulos. Esta cuestión ha sido uno de los instrumentos principales para garantizar cierta unidad nacional con respecto a los saberes comunes de cada nivel y modalidad expresados en incumbencias, alcances y perfiles de cada formación tanto en relación con las distintas jurisdicciones educativas cuanto en lo referente al régimen privado. De esto modo, el tema de la definición de parámetros comunes de conocimientos a transmitir, expresados en minimos comunes de instrucción general, planes de estudio, diseños curriculares compatibles, contenidos básicos comunes o núcleos de aprendizajes prioritarios fueron diversas medidas de política educativa referida a delimitar los saberes que se consideraron en cada momento histórico como socialmente significativos.

Desde el comienzo de la conformación del sistema educativo nacional en la segunda mitad del siglo XIX, se dictaron normas para la validez de los títulos de escuelas particulares. Con respecto a las escuelas y colegios particulares de nivel medio, por Ley 934 de 1978, los alumnos de colegios particulares podian rendir exámenes parciales o general en colegios nacionales de los estudios que hubieran cursado de nivel secundario. Además de la necesidad de rendir exámenes el plan de estudios debia comprender las mismas materias que la de los institutos nacionales y frente a tribunales formados por profesores de ambas instituciones (Art. 1 inciso $1^{\circ}$ ). Si cumplian estos requisitos se les extendía el certificado correspondiente aclarando el colegio de procedencia.

En el caso de colegios provinciales los alumnos se podían incorporar a las nacionales si cumplian con las mismas materias del plan de estudios de los colegios nacionales. (Art. 5).

Siguiendo los mismos mecanismos esta normativa se va extendiendo progresivamente a otras modalidades: en 1897 a las escuelas normales; en 1899 a las escuelas comerciales e industriales y en 1933 a las escuelas profesionales.

La estrategia seguida posteriormente fue dar mayor autonomía de decisión a las provincias y a las escuelas particulares. En el caso de las provincias, se reconocieron sus títulos en el en base a cuestiones meramente formales como la denominación del establecimiento, nombre del egresado, inserción de la leyenda referida a la validez establecida por decreto-ley $N^{\circ}$ $19988 / 72$ y firma de autoridades competentes. Asimismo, la estrategia fue extender progresivamente este mecanismo a las distintas modalidades y niveles.

Con respecto a la educación privada del ámbito nacional también estas instituciones fueron logrando mayor autonomía, principalmente, a partir de la creación de la Superintendencia Nacional de Educación privada (SNEP) en 1960 en que son consideradas unidades de gestión propia por lo cual tienen la capacidad de otorgar títulos sin rendir el examen en las escuelas públicas.

De lo expuesto se puede observar que progresivamente el Estado $\mathrm{Na}-$ cional fue flexibilizando y delegando en las jurisdicciones y las escuelas privadas la posibilidad de otorgar títulos con menores requisitos establecidos centralmente. 
Cuadro $N^{\circ}$ 1: Evolución de la normativa sobre validez nacional de títulos 1878-1972

\begin{tabular}{|c|c|c|c|}
\hline Año & Norma & Tema & Observaciones \\
\hline 1878 & Ley 934 & $\begin{array}{l}\text { - Reconoce saberes de escue- } \\
\text { las medias privadas previo } \\
\text { examen en escuelas publicas } \\
\text { - Los secundarios provinciales } \\
\text { solo en base a programas igua- } \\
\text { les }\end{array}$ & $\begin{array}{l}1897 \text { Se extiende a Escuelas } \\
\text { normales } \\
1899 \text { Se extiende a comerciales } \\
\text { e industriales } \\
1933 \text { Se extiende a escuelas pro- } \\
\text { fesionales } \\
\text { Otras modificaciones } \\
\text { Ley } 13047 / 49 \text { Altera el Art. } 5 \text { De- } \\
\text { termina hará un reglamento para } \\
\text { ingreso y promoción } \\
\text { Decrato } 12179 / 60 \\
\text { Creación del SNEP unidades de } \\
\text { gestión propia (otorgan títulos } \\
\text { con validez nacional) } \\
\text { Decreto } 9247 / 60 \text { Quiebra la su- } \\
\text { pervisión } \\
\text { Decreto } 15 / 64 \text { y } 371 / 64 \text { Quiebra } \\
\text { la equivalencia de programas }\end{array}$ \\
\hline 1954 & $\begin{array}{l}\text { Ley } 14389 \\
\\
\\
\text { Decreto } \\
\text { Reglamentario } \\
\text { 17087/56 } \\
\text { Ratificado por } \\
\text { Decreto-ley } \\
\text { 13315/57 }\end{array}$ & $\begin{array}{l}\text { Establece que sólo la nación } \\
\text { puede otorgar títulos validez } \\
\text { nacional para escuelas medias } \\
\text { privadas. } \\
\text { Se reconocen titulos provincia- } \\
\text { les de escuelas oficiales, si tie- } \\
\text { nen planes equivalentes y régi- } \\
\text { men de promoción y evaluación } \\
\\
\text { Los establecimientos provincia- } \\
\text { les pueden ser secundarios, nor- } \\
\text { males y comerciales, si tienen } \\
\text { los mismos planes y régimen de } \\
\text { calificación y promoción. Se } \\
\text { abre un registro de escuelas } \\
\text { (inspección periódica y análisis } \\
\text { de antecedentes) }\end{array}$ & $\begin{array}{l}\text { Modifica Art. } 5 \text { y } 6 \text { Ley } 934, \text { re- } \\
\text { ferido a las escuelas oficiales } \\
\text { provinciales } \\
\text { Derogados por ley } 19988 / 72\end{array}$ \\
\hline 1972 & $\begin{array}{l}\text { Ley } 19998 \\
\text { (Reglamentado } \\
\text { por Decreto 86/ } \\
73 \text { ) }\end{array}$ & $\begin{array}{l}\text { La validez (públicas y privadas } \\
\text { reconocidas) la determinan or- } \\
\text { ganismos provinciales,en base } \\
\text { a la escolaridad cumplida, los } \\
\text { contenidos mínimos propios de } \\
\text { los respectivos estudios y los } \\
\text { niveles globales de formación }\end{array}$ & $\begin{array}{l}\text { Invitan a provinciales a firmar } \\
\text { leyes de reciprocidad entre } \\
\text { ellas y enuncian la necesidad } \\
\text { de establecer estándares } \\
\text { comunes en todo el pais } \\
\text { Decreto } 1040 / 73 \text { modifica el } \\
\text { Decreto } 86 / 73 \text { para simplificar }\end{array}$ \\
\hline
\end{tabular}

\begin{tabular}{|c|c|c|c|}
\hline Año & Norma & Tema & Observaciones \\
\hline 1972 & $\begin{array}{l}\text { Ley } 19998 \\
\text { (Reglamentado } \\
\text { por Decreto 86/ } \\
73 \text { ) }\end{array}$ & $\begin{array}{l}\text { alcanzados. Luego la nación ha- } \\
\text { bilita los titulos cuya validez se } \\
\text { reconozca en virtud de lo esta- } \\
\text { blecido por esta ley. (Deroga ley } \\
14389 \text {, decreto } 17087 / 56 \text { ratifi- } \\
\text { cado por Decreto-ley } 13315 / 57\end{array}$ & $\begin{array}{l}\text { el tramite de validación de títu- } \\
\text { los y lo extiende a títulos docen- } \\
\text { tes provinciales oficiales } \\
\text { Decreto } 1606 / 74 \\
\text { (modifica Art. } 6 \text { decreto } 1040 \text { f } \\
\text { 73) Se extiende para títulos téc- } \\
\text { nicos provinciales medios o ter- } \\
\text { ciarios no docentes }\end{array}$ \\
\hline Decreto $N^{\circ} 8 / 72$ & & $\begin{array}{l}\text { Autoriza a los gobiernos provin- } \\
\text { ciales a dictar leyes de validez } \\
\text { provincial de títulos I de escue- } \\
\text { las nacionales y provinciales, } \\
\text { oficiales y no oficiales }\end{array}$ & $\begin{array}{l}\text { En virtud del mismo se dictan } \\
\text { distintas normas provinciales. }\end{array}$ \\
\hline & $\begin{array}{l}\text { Acuerdo de } \\
\text { Santa Fe IV } \\
\text { Reunión de } \\
\text { Ministros de } \\
\text { educación }\end{array}$ & $\begin{array}{l}\text { Establece que los estudios cur- } \\
\text { sados en establecimientos na- } \\
\text { cionales y provinciales de nivel } \\
\text { intermedio, medio y superior de } \\
\text { formación docente, oficiales y } \\
\text { privados incorporados y los ti- } \\
\text { tulos y certificados por ellos ex- } \\
\text { pedidos, tendrán validez para la } \\
\text { nación y provincias signatarias }\end{array}$ & \\
\hline
\end{tabular}

Fuente: Elaboración propia en base a normativa seleccionada

Con la creación del Consejo Federal de Educación Ley № 19682 / 72, se hará recurrente en las distintas reuniones la cuestión de la validez de nacional de títulos.

Finalmente, con la sanción de la LFE en 1993, se establece que es una atribución del Poder Ejecutivo: "Dictar normas generales sobre equivalencia de titulos y de estudios, estableciendo la validez automática de los planes concertados en el seno del Consejo Federal de Cultura y Educación" (Art. 53 inciso c). Asimismo, en la Ley de Ministerios de 1992 compete al Ministerio de Educación entender en esta materia (artículo 21, inciso c). Por lo tanto, las normas que se dicten serán de aplicación obligatoria en todas las jurisdicciones.

El Poder Ejecutivo Nacional dicta el Decreto 1276/1996 con el fin de establecer criterios comunes nacionales para acordar la validez nacional de los diferentes títulos de cada nivel del sistema educativo y aplicar la estructura creada por la LEF.

En este período se observa la debilidad del estado nacional para imponer sus regulaciones ante la disminución de incentivos financieros, que

$$
-71-
$$


aseguraran a las provincias la disposición de los fondos necesarios para la implementación de la Ley. El cuadro 2 muestra los problemas en la aplicación de la citada norma con las sucesivas modificaciones y prórrogas en la aplicación.

\section{Cuadro $\mathrm{N}^{\circ}$ 2: Modificaciones del Decreto $1276 / 1996$}

\begin{tabular}{|c|c|}
\hline Norma & Aspectos regulados \\
\hline Decreto 1276/96 & $\begin{array}{l}\text { - Regula criterios para dar validez nacional a los títulos } \\
\text { de todos los niveles del sistema educativo. } \\
\text { - Establece plazo de adecuación a la estructura creada por la LEF: } \\
\text { 1ero. de Enero del } 2001\end{array}$ \\
\hline Decreto $3 / 2000$ & $\begin{array}{l}\text { - Prorroga plazos de adecuación al 1ero. } \\
\text { De Enero de } 2003\end{array}$ \\
\hline Decreto $353 / 2002$ & $\begin{array}{l}\text { - Flexibiliza la aplicación de la estructura creada por al LEF } \\
\text { - Modifica criterios de validez nacional para las titulaciones } \\
\text { de la formación docente. } \\
\text { - Prorroga los plazos de adecuación al 1ero. De Enero de } 2005\end{array}$ \\
\hline Decreto 1394/2003 & $\begin{array}{l}\text { - Flexibiliza criterios de aplicación para las titulaciones de la formación docente. } \\
\text { - Deroga flexibilización de la aplicación de la nueva estructura de la LEF } \\
\text { establecida en el decreto } 353 / 2002 \text {. }\end{array}$ \\
\hline Decreto 209/2005 & - Prorroga la aplicación del Decreto al 1 de Enero de 2008. \\
\hline
\end{tabular}

Fuente: Elaboración propia en base a normas consultadas.

\section{Las políticas curriculares}

Una de las estrategias para lograr cierta unidad del sistema educativo en cuanto a logros comunes de los alumnos fue el establecimiento de objetivos y contenidos para cada nivel educativo que se encuentra relacionado con la validez nacional de los títulos.

La Ley 1420 de 1884, que regia para los establecimientos públicos y particulares de la Capital Federal y los territorios nacionales y que, luego de la sanción de la Ley 4874 de 1905 (Ley Láinez), se extiende a todas las escuelas nacionales creadas en territorios provinciales; establecía un mínimo de instrucción obligatoria (5). Asimismo, le correspondía al Consejo
Nacional de Educación creado en la ley 1420 entre otras funciones, "dictar los programas de la enseñanza de las escuelas públicas, con arreglo a las prescripciones de esta ley y necesidades del adelanto progresivo de la educación común" (Art. 57 inciso 11).

Según señala Puiggros A., durante el gobierno del Presidente Frondizi (1958-1962), en el marco de una politica desarrollista que fortaleció el planeamiento educativo con la creación de la Consejo Nacional de Desarrollo (CONADE), ordenó la cuestión docente y propició la transferencia de escuelas nacionales.

La autora señala que con la creación de la Comisión Permanente de Coordinación Escolar, por primera vez, se logra un acuerdo curricular básico de aplicación en todas las provincias y las escuelas nacionales (Puiggros, 1996).

El tema de un currículo básico común cobra un impulso sostenido a partir de la creación, en 1972 del Consejo Federal de Educación (CFE). En el marco de las deliberaciones de este organismo, se firma un conjunto de resoluciones y recomendaciones, que intentan establecer pautas comunes para todos los niveles y modalidades del sistema educativo.

La transferencia de escuelas nacionales concretada en 1978 incorporó en la agenda la necesidad de establecer contenidos comunes entre las distintas jurisdicciones. Por otra parte, cabe destacar que el establecimiento de acuerdos ente las jurisdicciones fue más sencillo ya que durante este período casi todo el tiempo se sucedieron gobiernos de facto.

En la V Asamblea Ordinaria del CFE, celebrada en Tucumán entre el 15 y 17 septiembre de 1976, por medio de la Resolución 2/76 se fijaron el fin, objetivos generales y agentes de la educación que servirán de lineamientos generales para el dictado de algunas leyes educativas provinciales.

En la IV Asamblea Extraordinaria del CFE, el 17 de diciembre de 1976, se aprobaron los objetivos pedagógicos del nivel primario y medio" y "los contenidos del nivel primario común" (Res.11/76). Se promovía esta política para lograr cierta unidad del sistema educativo a la vez que se dejaba espacios curriculares libres para adaptarse a los requerimientos de cada jurisdicción. Con los contenidos mínimos se trataba de ordenar definitivamente la vigencia del régimen de estudios estatuido por la Ley 19988 que determinaba la validez nacional de los títulos si se respetaban los contenidos mínimos, los niveles globales de formación alcanzados y los años de escolaridad cumplidos. El proceso de integración del curriculo propiamente dicho debia ser alcanzado por cada jurisdicción provincial de acuerdo con sus propias caracteristicas regionales *. 
Los contenidos básicos del ciclo básico del nivel medio se aprobaron, por la Recomendación $N^{\circ} 7 / 78$ de la VII Asamblea extraordinaria del CFE. Este nivel, se dividió en dos ciclos el básico y el superior, se establecieron los fundamentos de la determinación de contenidos, los objetivos del ciclo, la estructura organizativa de contenidos, las asignaturas y se establecieron pautas para la organización y orientación del desarrollo curricular. Luego de tres años de aplicación de estos contenidos se evaluó su aplicación, por medio de una encuesta a docentes, padres y alumnos. En la V Asamblea Ordinaria, dada las evaluaciones positivas de la aplicación de estos contenidos se recomendó extenderlos a todas las escuelas de cada jurisdicción (Recomendación. No 9/81).

Las resoluciones y recomendaciones sobre contenidos básicos del nivel medio superior fueron aprobadas en varias reuniones. En la V Asamblea ordinaria de diciembre de 1981 se decidió incorporar dos materas en los últimos años de la escuela media: Intereses Argentinos e Instrucción Cívica II (Resolución 6 /82). Finalmente, se aprueba por Recomendación. $N^{\circ} 6 / 83$ los contenidos mínimos del nivel medio- ciclo superior que incluye: objetivos pedagógicos del nivel medio, caracterización del educando, objetivos del ciclo superior, estructura del nivel medio, duración y grado, áreas curriculares del ciclo superior, porcentaje de tiempo de cada área, adopción del título del bachiller entre las más importantes.

Luego de transcurridos algunos años de la aplicación de los contenidos mínimos del nivel primario, se aprobó por Recomendación 8/82 las pautas para la evaluación cualitativa del nivel primario y la selección y jerarquización de los objetivos para la evaluación cualitativa y, en 1983, por Recomendación $N^{\circ} 1$ se aprobó la realización de la evaluación cualitativa del nivel primario en las jurisdicciones que pudieran hacerlo como mecanismos de asegurar la calidad de la educación.

El tema de la formación docente fue abordado en varias reuniones como una cuestión central de debate. Entre otras recomendaciones se destaca, la elaboración de un documento de "Pautas básicas para la formación docente en la Argentina" que contenia aspectos comunes para la carrera docente y específicos para el nivel primario y pre primario: estructura curricular, sistema de práctica y residencia, peso horario por área, sistema de evaluación y promoción, etc.

Con respecto al perfeccionamiento docente por la Recomendación 2/ 76 se recomendó el establecimiento de un Sistema Nacional de Perfeccionamiento Docente integrado por todos los organismos e instituciones, del ámbito oficial y privado que asuman la responsabilidad de formar o perfeccionar docentes en todos los niveles. Este sistema no se pudo poner en marcha por problemas de condiciones diferenciales institucionales y financieras de las provincias. Por ello, por Rec. 1/78 se decidió reemplazar el sistema por un Programa de Perfeccionamiento Docente para todos los niveles y modalidades, que suponía no crear nuevos entes sino coordinar acciones entre todas las jurisdicciones. Esta medida se articuló con la realización de un Seminario Nacional para el tratamiento del tema: Capacitación y perfeccionamiento, Principios y acciones que se realizó en la Ciudad de Bs. As el 28 de mayo del 1980 en que se elaboraron las bases para la organización del sistema federal de perfeccionamiento educativo.

Con respecto a la educación especial también se establecen criterios comunes (Recomendación 4 /78).

Con respecto a la educación de adultos, por la Recomendación. № $2 /$ 82 se estableció una politica unificada y se fijaron Pautas básicas formación y perfeccionamiento de los recursos humanos para la educación de adultos (Recomendación 8/79).

Se encuentra presente en varias reuniones del CFE la necesidad de coordinación de acciones entre la nación y las provincias, ya que ambas jurisdicciones tenían escuelas en los territorios provinciales. Entre otras se destacan, la Recomendación 2/73 sobre Metodologia para la racionalización de la distribución de los servicios educativos, el perfeccionamiento de los docentes, el intercambio de experiencias y toda otra temática que necesita la puesta en común y la Recomendación. No3 /83 que aprueba la metodologia y temática para la coordinación de acciones entre las jurisdicciones. Para lograr este objetivo se constituiria en cada provincia un comité coordinador cuya finalidad sería la de analizar, coordinar y proponer medidas sobre temas tales como: carta educativa, creación o fusión de establecimientos, compatibilización de documentos legales, intercambio de información, coordinación perfeccionamiento docente, estudio y compatibilización de la duración de las carreras, planes de estudios y alcance de los titulos.

Durante el gobierno de Alfonsín dada la composición del CFCYE de mayoría Justicialista, se hace más complejo el logro de consensos entre el estado nacional y las provincias. Por ello, no se realizan cambios sustanciales en materia curricular acordadas en este ámbito (ver Cuadro $N^{\circ} 1$ ). Sin embargo, cada jurisdicción educativa (Nación, provincias y la Municipalidad de la Ciudad de Buenos Aires) realizan cambios en materia curricular al interior de sus respectivos territorios. 
Cuadro $\mathrm{N}^{\circ}$ 3. Normas dictadas en el CFCYE

sobre política curricular 1984-1992

\begin{tabular}{|c|c|c|c|}
\hline Fecha & Autoridades & $\begin{array}{l}N^{\circ} \text { y tipo de } \\
\text { norma del CFCYE }\end{array}$ & Contenido \\
\hline $25 / 09 / 84$ & $\begin{array}{l}\text { Alfonsin, } \\
\text { Alconada } \\
\text { Aramburú }\end{array}$ & Recomendación $2 / 84$ & $\begin{array}{l}\text { Creación de la comisión permanente de } \\
\text { "contenidos curriculares básicos" }\end{array}$ \\
\hline $06 / 03 / 85$ & $\begin{array}{l}\text { Alfonsin, } \\
\text { Alconada } \\
\text { Aramburú }\end{array}$ & Resolución 2/85 & $\begin{array}{l}\text { Aprobación del informe de la comisión per- } \\
\text { manente de contenidos mínimos. }\end{array}$ \\
\hline $13 / 12 / 85$ & $\begin{array}{l}\text { Alfonsin, } \\
\text { Alconada } \\
\text { Aramburú }\end{array}$ & Recomendación 9/85 & $\begin{array}{l}\text { Convocatoria a la comisión permanente de } \\
\text { lineamientos curriculares. }\end{array}$ \\
\hline $06 / 07 / 90$ & $\begin{array}{l}\text { Menem, } \\
\text { Salonia }\end{array}$ & Resolución 7/90 & $\begin{array}{l}\text { Forma una comisión para elaborar una pro- } \\
\text { puesta de Diseño Curricular Base para la } \\
\text { formación docente }\end{array}$ \\
\hline $08 / 12 / 90$ & $\begin{array}{l}\text { Menem, } \\
\text { Salonia }\end{array}$ & Resolución 10/90 & $\begin{array}{l}\text { Conformar una Comisión Especial encarga- } \\
\text { da de estudiar criterios que permitan la ela- } \\
\text { boración de bases curriculares del nivel pri- } \\
\text { mario. Dicha Comisión se integrará con re- } \\
\text { presentantes del Ministerio de Educación y } \\
\text { Justicia de la Nación; de las distintas juris- } \\
\text { dicciones }\end{array}$ \\
\hline $25 / 11 / 92$ & $\begin{array}{l}\text { Menem, } \\
\text { Salonia }\end{array}$ & Resolución 23/92 & $\begin{array}{l}\text { Aprobar el documento preliminar «0bjeti- } \\
\text { vos por Nivel" que se integra como Anexo I } \\
\text { de la presente Resolución. Encomendar a } \\
\text { la Comisión de Asuntos Pedagógicos la re- } \\
\text { dacción final de los objetivos del Anexo l, y } \\
\text { el desarrollo conjunto de los Objetivos y los } \\
\text { contenidos. }\end{array}$ \\
\hline
\end{tabular}

Fuente: Elaboración propia en base a normativa del CFCYE.

De esta breve enumeración se constata la preocupación de establecer mínimos comunes en torno a los contenidos y objetivos de la educación en el país. Cabe destacar que todavia no se habia concretado la transferencia de escuelas del nivel medio y superior no universitario nacionales a territorios provinciales, por ello la nación participa también como prestador del sistema educativo. Esta situación cambiará con la transferencia de todas las escuelas a territorios nacionales que se concreta en 1992.
La LFE, establece una nueva distribución de atribuciones entre el Ministerio de Educación nacional, los gobiernos provinciales y el CFCYE. EI ministerio nacional será el ámbito de formulación y ejecución de políticas a nivel nacional, los ministerios provinciales serán el ámbito de formulación y ejecución de políticas a nivel jurisdiccional y el CFYCE será el ámbito de coordinación y concertación del Sistema Nacional de Educación.

Con respecto al tema de la fijación de contenidos mínimos determina que el Ministerio de Nacional establecerá, en acuerdo con el CFCYE, los objetivos y contenidos básicos comunes de los currículos de los distintos niveles, ciclos y regímenes especiales de enseñanza que faciliten la movilidad horizontal y vertical de los alumnos/as dejando abierto un espacio curricular suficiente para la inclusión de contenidos que respondan a los requerimientos Provinciales, Municipales, Comunitarios y Escolares (artículo 53 inciso b). Asimismo, compete al Ministerio Nacional, dictar normas generales sobre equivalencia de títulos y de estudios, estableciendo la validez automática de los planes concertados en el seno del Consejo Federal de Cultura y Educación (artículo 53 inciso c).

Por otra parte, son los Ministerios provinciales los responsables de aprobar el currículo de los diversos ciclos, niveles y regímenes especiales en el marco de lo acordado en el Consejo Federal de Cultura y Educación y aplicar con las correspondientes adecuaciones, las decisiones del Consejo Federal de Cultura y Educación ( artículo 59 inciso b y d)

Finalmente, al CFCYE le corresponde: a ) concertar dentro de los lineamientos de la política educativa nacional los Contenidos Básicos Comunes, los diseños curriculares, las modalidades y las formas de evaluación de los ciclos, niveles y regímenes especiales que componen el sistema (Art. 56 inciso a); b) acordar los mecanismos que viabilicen el reconocimiento y equivalencia de estudios, certificados y títulos de la educación formal y no formal en las distintas Jurisdicciones (Art. 56 inciso b); c) acordar los Contenidos Básicos Comunes de la Formación Profesional Docente y las acreditaciones necesarias para desempeñarse como tal en cada ciclo, nivel y régimen especial (Art. 56 inciso c) y, d) acordar las exigencias pedagógicas que se requerirán para el ejercicio de la función docente en cada Rama Artística en los distintos Niveles y Regímenes especiales del Sistema (Art. 56 inciso d).

A partir de esta delimitación de funciones entre estos tres organismos, promovido por el Ministerio Nacional, previa consulta a expertos de todas las disciplinas se van estableciendo los contenidos básicos comunes (CBC) para todos los niveles y modalidades. (6)

Los procedimientos y circuitos para acordar los CBC, fueron estableci-

$$
-77-
$$


dos por la Resolución No 26/93 (CFCYE). Dentro de los Aspectos Prioritarios para la Aplicación de la LFE, solo dos transformaciones requerian pasar por cinco circuitos: la transformación curricular y la capacitación docente.

Los circuitos establecidos por el CFCYE. fueron cinco, coordinados por la Secretaría de Programación y Evaluación Educativa, del Ministerio de Cultura y Educación y el Comité Ejecutivo del CFCYE.(Anexo de la Resolución $N^{\circ} 26 / 93$, Documento Serie O No1, Capitulo IV): $1^{\circ}$ ) el circuito técnico: se preveía la elaboración de documentos técnicos para consultas y acuerdos y de los documentos de trabajo "Serie A", por la Secretaria de Programación y Evaluación Educativa; $2^{\circ}$ ) el circuito dos: Consulta federal, de consultas a las jurisdicciones, en los Ministerios de la Nación y los jurisdiccionales; $3^{\circ}$ ) el circuito tres: Consulta Nacional, a la sociedad.; $4^{\circ}$ ) el circuito cuatro: Acuerdos federales. Sintesis de acuerdos transitorios, por los ministerios nacionales y jurisdiccionales y, $5^{\circ}$ ) el circuito cinco: de normativa nacional y provincial: de implementación de la LFE, por los poderes ejecutivos nacional y legislativos y ejecutivos provinciales.

El mecanismo para la aprobación de los documentos fue, luego de la consulta a expertos de las disciplinas, habilitar la discusión de los documentos a partir de diferentes circuitos. Para el circuito de consulta nacional, se había establecido diseñar un cuestionario sobre los documentos, luego se los remitiria a entidades de actuación en el ámbito nacional su consulta y posterior incorporación de enmiendas a los documentos para ser elevadas a la Asamblea del CFCYE, con el objetivo de elaborar los acuerdos de mediano plazo. La lista de entidades de actuación en el ámbito nacional consultadas, se ampliaría a otras personalidades de actuación destacada para recabar su opinión.

La primera selección de los Contenidos Básicos Comunes tuvo un proceso de consulta a diferentes sectores de la comunidad. Esto estaba previsto en el Anexo de la resolución No 26/93 aprobado por el CFCYE.

El trabajo técnico, estaba organizado por áreas de consulta, las cuales eran dirigidos por coordinadores seleccionados directamente por la Secretaria de Educación. Hubo distintas tipos de consultas. Entre ellas la consulta académica consistía en seleccionar tres consultores que debian tener ciertas condiciones académicas, entre ellas el prestigio de pertenecer a una entidad reconocida o un recorrido histórico importante en lo académico, se consultaron a alrededor de seiscientos académicos. Los consultores trabajaban para una disciplina especifica, a través de un cuestionario de tres preguntas, una de las cuales preveía un intercambio con otros diez académicos. La consulta a la opinión pública se realizó a través de

$$
-78-
$$

diarios o por teléfono. Hubo encuestas a docente, a Organizaciones No Gubernamentales (ONGs) y organismos intermedios.

La compatibilización de las diferentes posturas era responsabilidad de cada coordinador. Luego se elaboraba un documento borrador que era discutido con otros miembros, y en algunos casos esto servia para reelaborar el documento original. Una vez elaborado un último documento y aceptado técnicamente, entraba en otros circuitos de consulta. Era puesto a discusión con los técnicos de las regiones del Consejo Federal, la idea era llegar a un consenso previo a la reunión del Consejo. El coordinador técnico del nivel central trabajaba con los Ministros de educación provinciales y sus cuerpos técnicos, por regiones.

Uno de los inconvenientes que se suscitaron durante ésta fase, fue que materiales para la discusión no fueron enviados con anticipación a las provincias, en el caso de los Seminarios regionales algunas provincias mandaban a sus técnicos sin criterios específicos. Los gremios no opinaron porque reclamaban una mayor participación en las decisiones.

Los Contenidos Básicos Comunes, elaborados en el Ministerio de Educación, por un grupo de técnicos, especialmente convocados para su elaboración, fueron aprobados por primera vez el 29 de noviembre de 1994 por la Resolución No $39 / 94$ del Consejo Federal de Educación. Ésta primera aprobación suscitó una serie de críticas por parte de la Iglesia Católica lo que produjo un serio conflicto, que culminó con la introducción de cambios en tales contenidos, tras un acuerdo entre el Ministerio de Cultura y Educación (M.C.y E.) y la Iglesia Católica.

La reforma curricular incluía tres niveles de especificación: el federal a cargo del CFCYE; el jurisdiccional a que implicaba la elaboración de los diseños curriculares a partir de los CBC de cada nivel y modalidad y el de cada escuela que implicaba un proyecto propio a partir de lo establecido en los otros dos niveles.

Ante el fracaso de los CBC, dado los resultados dispares en términos de los aprendizajes reales de los alumnos, durante el Ministerio de Filmus, por Resolución N $N^{\circ} 214$ de abril del 2004 CFCYE se propone la identificación de núcleos de aprendizaje prioritarios (NAP) desde el nivel inicial hasta la educación Polimodal/ media secuenciados por años. Los NAP hacen referencia a un conjunto de saberes centrales relevantes (problemas, temas y preguntas principales de las áreas y disciplinas) y a sus formas distintas de descubrimiento/ razonamiento y expresión significativos, que incorporados como objetos de enseñanza contribuyen a desarrollar, construir y ampliar las posibilidades cognitivas, expresivas y sociales de los niños y jóvenes. Con esta política se pretendia garantizar una base común 
y equivalente de aprendizajes para reducir las desigualdades existentes y que fueran referentes para: la tarea docente, la información y participación de las familias, formalización de compromisos de acción entre las jurisdicciones, los procesos de evaluación de la calidad y las decisiones relacionadas con la movilidad interjurisdiccional de los alumnos. El Ministerio elaboró documentos y de materiales de apoyo para la tarea docente y de orientación para padres.

El breve tiempo transcurrido desde la formulación de los NAP no permiten una evaluación exhaustiva de esta politica, sin embargo, algunas personas manifiestan su preocupación sobre una posible disminución de exigencias con respecto a lo establecido en los CBC.

\section{Las políticas sobre financiamiento de la educación}

Desde los inicios conformación del sistema educativo nacional el problema de asegurar un adecuado financiamiento fue una preocupación central del gobierno nacional. Se diseñaron diferentes tipos de políticas primero a través de subvenciones y luego creando directamente esuelas en la provincias de dependencia nacional.

Sancionada la Constitución Nacional en 1853 se planteó la necesidad de asegurar el desarrollo de la educación básica cuya prestación fue responsabilidad de las provincias (artículo $5^{\circ}$ Constitución Nacional). Como las provincias tenian problemas financieros para garantizar la educación primaria, existen antecedentes desde la época de la Organización Nacional, en el que gobierno nacional sancionó diferentes leyes de subvenciones para ayudar a las provincias en esta área. Se destacan un conjunto de leyes. Las leyes 153 y 164 de 1857 fueron sancionadas por el Congreso de Paraná de la Confederación Argentina y autorizan al Poder Ejecutivo a subvencionar a las provincias, estos fondos los distribuiría el Ministerio de Instrucción pública según los informes provinciales sobre inversión. La Ley 153 destinaba fondos a las provincias para la construcción de edificios, compra de mobiliario, libros y útiles y sueldos de los maestros. El Poder Ejecutivo controlaba la aplicación de los fondos y promovía la constitución de comisiones especiales elegidas por los vecinos para administrar dichos fondos.

Dos leyes sancionadas por el Congreso de la Nación retomarán el tema de la transferencia de fondos para el sostenimiento de las escuelas provinciales. La ley 463 de 1871 organiza y sistematiza la forma el monto y las condiciones que serán entregados los subsidios a las escuelas de las provincias y crea una organismo nacional que administra los fondos. La 2737 de 1890 de Fomento a la Instrucción Primaria a las Provincias establecía fines para su asignación de los subsidios. Entre ellos se destacan la construcción y equipamiento de escuelas y el pago a los docentes. Las provincias para recibir este apoyo pecuniario debian comprometerse a invertir por lo menos un $10 \%$ del presupuesto provincial al sostenimiento de la educación, además de otros requisitos de orden administrativo y pedagógico. Un tema interesante de la Ley 2737 es que establecía una distribución diferencial entre provincias según a la proporción invertida en educación.

Con la Ley 4874 de 1905 , se cambia la lógica de promoción de la instrucción primaria por parte de la Nación y se decide la creación de escuelas nacionales en territorios provinciales a pedido de las jurisdicciones. Se aducía que el anterior mecanismo no fue exitoso ya que las provincias muchas veces destinaban los fondos de las subvenciones a otros sectores y desde las provincias cuestionaban el retraso en la recepción de los mismos. Por la Ley 18586 de 1970 se deroga la Ley 4874.

Con la Ley 1420 que regía originalmente para las escuelas situadas en la Capital Federal y los territorios nacionales y luego para las escuelas creadas en virtud de la Ley Láinez, incluia un capitulo especial de financiamiento. Como en otros temas resultó innovadora ya que crea un Fondo Permanente Escolar para asegurar un financiamiento adicional para las escuelas que quedará librado de la disputa sectorial para el reparto de fondos entre las políticas públicas de los otros sectores de gobierno. Es fondo se formaba de diferentes tipos de recursos.

Asimismo, por Ley 16727 del año 1965, se crea un Fondo Escolar Permanente, destinado exclusivamente para construir o mejorar edificios escolares y asegurar su adecuado financiamiento.

Hubo asimismo, muchas leyes que creaban impuestos especiales con asignación especifica para la educación. Por ejemplo la decreto- ley 8718/ 57 que imponía un impuesto sobre todas las entradas cinematográficas y teatrales exclusivamente destinado para la edificación escolar. Otro ejemplo fue en 1998, el establecimiento de un impuesto adicional sobre los automotores para cubrir el Fondo de Incentivo Docente.

En la década del '60 se empieza a debatir la transferencia de los servicios educativos a las provincias y nuevamente el tema del financiamiento resultará un tema conflictivo en la concreción de esta política. La transferencia de escuelas fue incluida como un artículo dentro de las leyes de presupuesto de 1960 y 1961 como una politica que apuntaba principalmente a solucionar un problema fiscal (7). Por ello, estos primeros intentos tuvieron resultados muy limitados. Posteriormente, en el gobierno militar de Onganía en 1968, se retoma esta discusión en diferentes reuniones de

$$
-80-
$$


Ministros de Educación de las provincias. La marcha del proceso de transferencia fue lenta hasta 1976, ya que las provincias no consideraban que se aseguraba un adecuado financiamiento para el sostenimiento de las escuelas transferidas. En 1978, por las Leyes 21809 y 21810 se transfieren la casi totalidad de las escuelas primarias comunes y de adultos a las provincias. Nuevamente en 1992, se retoma el tema a partir de la sanción de la Ley 24049 por la cual se transfieren las escuelas de nivel medio y superior no universitario a las provincias.

Diversos estudios consideran que este proceso de transferencia se hizo más por razones fiscales que políticas y pedagógicas (Filmus, 1997; Di Gropello, 1999). Es decir, que la necesidad de achicar los gastos del gobierno nacional sin adecuadas garantías de financiamiento provincial produjo un deterioro de la calidad de la educación. Se desatendieron o cerraron escuelas de adultos, se desmejoró o no incrementó adecuadamente la infraestructura edilicia y el equipamiento escolar y se deterioraron los salarios docentes. (8)

La situación salaria! de los docentes empieza a convertirse en un problema de difícil resolución que lleva en 1998 a crear por medio de la Ley 25053 del Fondo Nacional de Incentivo Docente, por el cual se crea dicho fondo a partir de la creación de un impuesto a los automotores de asignación específica. El conflicto generado en el interior del propio gobierno nacional, las resistencias de los sectores afectados por el gravamen terminado por eliminar en el año 1999 dicho gravamen pero con la continuación de dicho fondo con recursos del Estado nacional. Esta ley fue prorrogada por la Ley 26.057 por cinco años a partir del 1 de Enero del 2004.

En cumplimiento de lo establecido por el artículo 63 de la LFE se firma en el año 1994 el Pacto Federal Educativo con los gobernadores de las provincias y del Intendente de la Ciudad de Buenos Aires -ratificado por Ley 24856 de 1997 - que establecia una serie metas que se preveía cumplimentar en el periodo septiembre 1994-1999 que se resumen agrupadas según temáticas en el cuadro 4.

\section{Cuadro 4: Metas Pacto federal Educativo}

\begin{tabular}{|l|l|l|l|}
\hline Temática & Objetivo & Magnitud & $\begin{array}{l}\text { Fecha de } \\
\text { concreción }\end{array}$ \\
\hline $\begin{array}{l}\text { Infraestructura } \\
\text { edilicia }\end{array}$ & $\begin{array}{l}\text { Erradicación de escuelas rancho en } \\
\text { todo el territorio nacional }\end{array}$ & $100 \%$ & $\begin{array}{l}\text { septiembre } \\
\text { diciembre de 1994 }\end{array}$ \\
\cline { 2 - 4 } & $\begin{array}{l}\text { Erradicación de establecimientos } \\
\text { educativos precarios }\end{array}$ & $100 \%$ & $1995-1998$ \\
\hline
\end{tabular}

\begin{tabular}{|c|c|c|c|}
\hline Temática & Objetivo & Magnitud & $\begin{array}{l}\text { Fecha de } \\
\text { concreción }\end{array}$ \\
\hline \multirow{3}{*}{$\begin{array}{l}\text { Infraestructura } \\
\text { Edilicia }\end{array}$} & Aumento de la capacidad instalada & $20 \%$ & 1995-1999 \\
\hline & $\begin{array}{l}\text { Mejoramiento del estado edilicio de } \\
\text { características deficitarias }\end{array}$ & $100 \%$ & 1995-1999 \\
\hline & $\begin{array}{l}\text { Incorporación de los establecimientos } \\
\text { a la nueva estructura }\end{array}$ & $100 \%$ & $1995-1999$ \\
\hline \multirow[t]{3}{*}{ Equipamiento } & $\begin{array}{l}\text { Equipamiento de infraestructura } \\
\text { informática en unidades educativas } \\
\text { que cuenten con minimas condiciones } \\
\text { para su instalación }\end{array}$ & $100 \%$ & $1995-1999$ \\
\hline & Bibliotecas escolares & $100 \%$ & $1995-1999$ \\
\hline & $\begin{array}{l}\text { Material pedagógico general, básico } \\
\text { de investigación y elementos } \\
\text { audiovisuales acorde con la } \\
\text { transformación educativa en curso }\end{array}$ & $100 \%$ & $1995-1999$ \\
\hline \multirow{3}{*}{$\begin{array}{l}\text { Expansión de } \\
\text { la matricula }\end{array}$} & Escolarización de los niños de 5 años & $100 \%$ & $1995-1999$ \\
\hline & $\begin{array}{l}\text { Escolarización de niños y adolescentes } \\
\text { de } 6 \text { a } 14 \text { años }\end{array}$ & $100 \%$ & 1995-1999 \\
\hline & $\begin{array}{l}\text { Escolarización de adolescentes } \\
\text { de } 15 \text { a } 17 \text { años }\end{array}$ & $100 \%$ & 1995-1999 \\
\hline $\begin{array}{l}\text { Capacitación } \\
\text { docente }\end{array}$ & $\begin{array}{l}\text { Generalización de la capacitación } \\
\text { docente acorde a la transformación } \\
\text { educativa en curso }\end{array}$ & $100 \%$ & 1995 \\
\hline \multirow{3}{*}{$\begin{array}{l}\text { Mejoramiento } \\
\text { de la eficiencia } \\
\text { del sistema } \\
\text { educativo }\end{array}$} & Disminución del índice de repitencia & $50 \%$ & $1995-1999$ \\
\hline & Disminución del analfabetismo absoluto & $50 \%$ & $1995-1999$ \\
\hline & $\begin{array}{l}\text { Mejoramiento progresivo del } \\
\text { rendimiento escolar }\end{array}$ & - & $1995-1999$ \\
\hline
\end{tabular}

En el año 2000 durante el gobierno del presidente De La Rúa, su primer Ministro de Educación, Juan LLach, propone la firma del Pacto Federal II. Por Resolución 135/2000 del CFCYE se habilita la discusión del documento Bases para el Pacto Federal Educativo II que duraría hasta fines del 2007. Este Pacto no se concreta al no establecerse un consenso entre las jurisdicciones educativas. 
Esta propuesta incluía objetivos, metas y núcleos de reformas. Se reconocía la necesidad de disminuir las diferencias educativas asegurando una educación de calidad para todos.

Eran sus objetivos y Metas

1. Metas explicitas a alcanzar en escolaridad neta y graduación a tiempo en los niveles inicial, EGB-primario y Polimodal- secundario.

2. Extensión gradual de la obligatoriedad de la enseñanza, con un cronograma cierto, hasta alcanzar a las edades de 3 a 18 años.

3. Estándares nacionales y provinciales de calidad educativa, medibles en términos de los aprendizajes de los estudiantes, y plazos para su evaluación sistemática y su cumplimiento

4. Nuevos plazos para la vigencia efectiva de las metas establecidas en la Ley Federal y sus normas complementarias. (9)

Esta propuesta, comprometía (hasta el año 2007) 7400 millones de pesos más un porcentaje en caso de aumento de la recaudación impositiva Cada año el monto ascendia a 1060 millones, en este incluía el Fondo de Incentivo Docente de 660 millones y 440 millones para el Fondo Domingo Faustino Sarmiento.

El contenido del Pacto, que incluía propuestas que eran de neto corte neoliberal fue ampliamente rechazado por sectores gremiales y politicos tanto del oficialismo como de la oposición. Los ministros peronistas consideraban insuficiente los montos comprometidos por la Nación, asi como aspectos del contenido concreto, además los sectores gremiales añadian serias críticas al contenido de muchos de sus puntos especialmente los referidos a la carrera docente y los criterios de incremento salarial. La CTERA llamaba a un paro si no se pagaba el incentivo en término y a otro si se firmaba el Pacto Federal II.

Con la renuncia temprana de Llach a la cartera educativa y la asunción del Ministro Juri este tema no vuelve a discutirse.

El tema del financiamiento se vuelve a retomar con fuerza durante el año 2005 en que Filmus plantea una nueva estrategia, que se concretó con el dictado de una Ley de Financiamiento educativo $\mathrm{N}^{\circ} 26075$, que dado el incumplimiento de lo previsto en la Ley Federal de Educación oportunamente en el Art. 64 de la Ley Federal de Educación.

Esta redefine un nuevo diseño de política sobre esta temática, creando un fondo específico de recursos coparticipables de acuerdo a lo establecido en el art. 75 inciso 3 de la Constitución Nacional. Dichos recursos serán distribuidos de acuerdo a una fórmula establecida en la citada norma en donde se considera la matrícula de la jurisdicción, el índice de ruralidad y la población no escolarizada de niños y jóvenes entre 3 y 17 años (Art.8). El objetivo central es lograr el aumento de la inversión educativo al $6 \%$ del PBI para el año 2010. A su vez la ley establece una serie de mecanismos para distribuir los recursos, acordar anualmente la distribución de recursos y las metas a lograr desde el punto de vista educativo.

\section{Conclusiones}

La cuestión de la relación Nación - Provincias en Argentina a nivel general, y en politica educativa en particular, ha sido un problema que surge con la misma constitución del Estado Argentino.

Reconocer que en el momento actual existe un conflicto en relación al tema, implica poder entender esta situación en el devenir histórico, del que se pueden extraer continuidades y rupturas. También implica comprender el problema educativo en el marco de cuestión más amplia que afecta a todas las áreas de gobierno en donde existen atribuciones compartidas entre ambas instancias territoriales.

El presente trabajo ha delineado, por una parte, las modificaciones que se fueron dando desde el punto de vista del gobierno del sistema educativo a partir de la arquitectura constitucional de 1853 y, por otra, las relaciones que se fueron estableciendo entre la Nación y las provincias en diferentes contextos con respecto a los instrumentos politicos utilizados para dar unidad al sistema educativo.

En primer término, se explicó como se dio este proceso referido a la prestación de los servicios educativos. La acción concurrente entre $\mathrm{Na}$ ción y las Provincias en la creación y sostenimiento de instituciones educativas desde los inicios de la configuración del sistema educativo nacional a fines del siglo XIX con la fuerte presencia del Estado central, particularmente, en el nivel medio y superior-universitario y la posterior prestación en el nivel primario a partir 1905 significó un proceso de centralización educativa paralelo a la consolidación del Estado Nacional Argentino.

El proceso paulatino de transferencias de escuelas nacionales a las jurisdicciones educativas borró esta particular forma de presencia del Estado Nacional, y se tradujo en cierta descentralización operatịa. Las interpretaciones constitucionales sobre las potestades del nivel nacional para prestar dichos servicios constituyeron verdaderas luchas conceptuales.

En el caso particular de la validez nacional de los títulos la estrategia del Estado nacional fue clara en los inicios: respetar los mismos contenidos, expresado en la exigencia de tener los mismos programas de estudios, y para el caso de las instituciones privadas de nivel medio rendir los 
exámenes en instituciones públicas. Por diversas vías el proceso inicial se fue modificando históricamente mediante la autonomización del sector privado y la falta de normas en relación a los mínimos exigibles, cargas horarias, entre otros.

Con la sanción de la LFE se intenta retomar esta modalidad de control y supervisión del Estado Nacional en los títulos de todos los niveles (con excepción del sector superior universitario, cuyas normas merecen otro tipo consideraciones), pero lo analizado muestra con claridad la imposibilidad de aplicación del cuerpo normativo planteado básicamente con el Decreto $1276 / 96$. Las sucesivas postergaciones en su aplicación y una serie de modificaciones referidas a las exigencias y requisitos para otorgar validez nacional en las titulaciones ha terminado por convertirla en una norma de dudosa eficacia en los hechos y cuyo prolongación en el tiempo supone dejar latente un problema no menor en el sistema nacional que es reconocer las titulaciones en cada uno de los niveles del sistema.

En materia de regulación de curriculo, siempre existieron estrategias en donde se trató de establecer criterios nacionales acerca del mínimo en materia de contenidos desde la Ley 1420 en adelante. La fuerte presencia en la prestación de los servicios educativos por parte de la Nación se convirtió en el verdadero motor de las políticas curriculares.

Esta cuestión se modificó a partir de los procesos de descentralización que culminan en el año 1992 y con la sanción de la LFE. De ahora en más la cuestión de los lineamientos curriculares nacionales se establecen como prioridad de la politica para buscar unidad en el sistema. No obstante, se muestra en el trabajo los inconvenientes para aplicar dichos criterios, tanto en su elaboración cuanto en su puesta en práctica en la construcción de los CBC a nivel nacional y los respectivos diseños curriculares jurisdiccionales por el otro. La decisión de la construcción de los denominados Núcleos de Aprendizajes Prioritarios ha pretendido corregir los problemas detectados en la politica reseñada pero su aplicabilidad y eficacia merecen análisis particulares.

Las estrategias en materia de financiamiento han sido también modificadas en el tiempo, desde los subsidios otorgados a las provincias a través de las leyes nacionales hasta las estrategias. de creación directa de servicios en las provincias fueron utilizadas por la Nación para avanzar en la ampliación de la cobertura del sistema educativo. Pero el proceso. sucesivo de retiro del Estado central en el tiempo, fue suplantado con estrategias de tipo compensatorias como la modalidad implementada a partir del Pacto Federal I en la década de los noventa. Su cumplimiento parcial, y los sucesivos conflictos gremiales docentes dieron por resultado una se- rie de normas complementarias en materia de financiamiento como el Fondo de Incentivo Docente, también de dificultosa aplicación y cumplimiento en el tiempo.

Con la sanción de la nueva Ley de Financiamiento Educativo se intenta establecer nuevas reglas de juego en esta materia entre las competencias y responsabilidades del Estado Nacional y las jurisdicciones, su nivel de cumplimiento, el nivel de los aportes entre la Nación y las jurisdicciones, y los problemas de estas últimas en cumplir con las diversas metas propuestas abre un nuevo capítulo de tensiones en esta historia.

Nuestro objetivo fue mostrar tensiones, contradicciones en las diferentes modalidades de regulaciones e intervenciones en torno a la relación entre la Nación y las provincias en materia de gobierno educativo. Las politicas diseñadas y los instrumentos utilizados en no pocos casos terminaron en fracasos, y en otros evidenciaron inaplicabilidad. Tal vez por ello resulte fundamental a partir de las experiencias reseñadas volver a mirar de manera compleja estos temas para encontrar alternativas posibles y viables.

\section{Notas Bibliográficas:}

* Los contenidos de la primaria común se estructuraron según las siguientes áreas: lengua, matemática, estudios sociales, ciencias elementales básicas, educación musical, educación práctica y educación física. Se consideraron tres ciclos, el primero abarcaba $1^{\circ}, 2^{\circ}$ y $3^{\circ}$ grado; el segundo, $4^{\circ}$ y $5^{\circ}$ grado y el tercero, $6^{\circ}$ y $7^{\circ}$ grado.

(1) Existieron numerosas leyes que regularon el sistema universitario, sólo una que reguló la primaria común y de adultos y aplicable sólo en la jurisdicción nacional ( Ley 1420), en el nivel medio sólo se reguló por ley el mecanismo del otorgamiento de titulos de la enseñanza privada (Ley 934) y la enseñanza técnica ( Ley de creación del CONET).

(2) La palabra legislación está empleada en su sentido sustancial, es decir toda norma jurídica obligatoria impuesta por autoridad pública. Esta admite, uno formal referente al acto juridico sancionado por el Congreso y promulgado por el Poder Ejecutivo. En su sentido sustancial que es más amplio incluye desde la Constitución hasta las decretos y resoluciones de los ejecutivos.

(3) Hans Kelsen reconocido teórico del derecho desarrolla ampliamente esta problemática en su conocida obra Teoria Pura del Derecho.

(4) Esta Ley se aprueba con la mayoria propia con que contaba el partido oficial más algunos partidos provinciales y con el rechazo de la UCR y el FREPASO, los dos partidos más importantes de la oposición, También se destaca en algunos estudios que el sector de la enseñanza privada y la Iglesia católica en particular fueron otro de los aliados importantes del gobierno en el momento de aprobación de la norma ya que se respetaron y ampliaron en esta ley sus

$$
-86-
$$$$
-87-
$$ 
reclamos históricos. Nosiglia M. C., Marquina, M. (1993), «Ley Educación. Aportes para el análisis y el debate", en Revista Propuesta Educativa, nro. 9, FLACSO, Bs. As.

(5) Art. 6- El «mínimum» de instrucción obligatoria comprende las siguientes materias: lectura y escritura; aritmética (las cuatro primeras reglas de los números enteros, y el conocimiento del sistema métrico decimal y la ley de monedas, pesas y medidas); geografia particular de la República y nociones de geografia universal, historia particular de la República y nociones de historia general, idioma nacional; moral y urbanidad; nociones de higiene; nociones de ciencias matemáticas, fisicas y naturales; nociones de dibujo y música vocal; gimnástica, y conocimiento de la Constitución nacional. Para las niñas será obligatorio además el conocimiento de labores de manos y nociones de economía doméstica. Para los varones el conocimiento de los ejercicios y evoluciones militares más sencillos, y en la campaña, nociones de agricultura y ganadería.

(6) Le Ley de Educación Nacional 26206, no modificó sustancialmente esta distribución de funciones entre los organismos.

(7) Con la sanción de la Ley 12.139 a partir de 1935 se estableció el primer régimen de unificación y coparticipación de impuestos internos. Dicha cuestión es central en nuestro régimen fiscal. Basta señalar el debate que se dio en la Convención Constituyente de 1994 sobre el tema y el incumplimiento en establecer un nuevo esquema de coparticipación federal.

(8) El artículo 26 de la ley 24.049 de descentralización intenta salvar el problema del financiamiento al señalar en su artículo 26: "Ios participantes en el sistema de ley 23.548, deberán presentar en el periodo legislativo de 1992 un proyecto de ley sustitutiva del régimen vigente de coparticipación federal de impuestos". Aspecto que obviamente no fue cumplido.

(9) Se establecian un conjunto de políticas ordenadas en seis capítulos temáticos: a)- Jerarquización de la a profesión docente; b) Calidad de la educación : c) Equidad de la educación ; d) Reformas institucionales y, e) Fondo Domingo Faustino Sarmiento

\section{Referencias Bibliográficas:}

- AGULLA, J.C. (1967). Integración Nacional y Federalismo Educativo. En: AGULLA, J.C. Federalismo y centralismo. Ediciones Libera, Bs. As.

- ALBERGUCCl, R. (1995). Ley Federal y Transformación Educativa, Troquel, Bs. As.

- BOTANA, N.(2004). La gobernabilidad en el del régimen federal argentino. Notas sobre la educación pública. En: TENTI, E. (org.) Gobernabilidad de los sistemas educativos en América Latina, IIPE-UNESCO, Buenos Aires.

- BRAVO, H. (1972). Bases constitucionales de la educación argentina, Paidós, Buenos Aires,

- BRAVO, H. (1983). Educación Popular. Centro Editor de América Latina, Buenos Aires.
- DI GROPELLO, E. (1999). Los modelos de descentralización educativa en América Latina. En Revista de la CEPAL, $N^{\circ} 68$, Santiago de Chile.

- FERNANDEZ LAMARRA, N.(1986). Federalismo y centralismo en la política y en la administración de la educación argentina. Ponencia presentada en el Congreso Nacional de Federalismo Argentino, Santa Fe.

- FILMUS, D. (1997). La descentralización educativa en Argentina: elementos para el análisis de un proceso abierto. Ponencia presentada en el Coloquio Regional sobre Descentralización de la Educación, CLAD, Costa Rica, 1997.

- MONTENEGRO, A (1988). Interpretación del artículo $5^{\circ}$ de la Constitución Nacional. En: AAVV. Gobierno y administración de la educación, EUDEBA Buenos Aires.

- NOSIGliA, M.C., MARQUiNA, M. (1993). Ley de Educación. Aportes para e análisis y el debate. En: Revista Propuesta Educativa, N. 9, FLACSO, Bs. As

- NOSIGLIA, M. C., MARQUINA, M. (1996) La reforma educativa argentina de los ' 90 en el marco del ajustre estructural. Ponencia presentada en las "Jornadas de estado y Sociedad. Nuevas Reglas de Juego". Universidad de Buenos Aires.

- PAVIGLIANITI, N. (1998). Diagnóstico de la Administración Central de la Educación. Ministerio de Educación y Justicia, Buenos Aires.

- PUIGGROS, A. (1996). ¿Qué pasó en la educación argentina? Desde la con quista hasta el menemismo, Kapelusz, Buenos Aires.

- TIRAMONTI, G., NOSIGLIA, M.C. (1991). La normativa educativa de la transición democrática, OFYL, Buenos Aires. 